\title{
Examining Management History Through The Lens Of Critical Biography
}

Jane Whitney Gibson, Nova Southeastern University, USA

\begin{abstract}
This paper builds a case for using the qualitative methodology of critical biography to illuminate the life, times, and contributions of pioneers in the field of management history. First the importance of management history is discussed and the critical biography methodology is described. Then, the methodology is applied to management history through examining several articles using the methodology including articles about Mary Parker Follett and Rhona Rapaport. Pros and cons of using the methodology are discussed including approachability and high interest level as pros and necessity to make inferences and the close interplay between researcher and research as cons. Implications for future research are presented.
\end{abstract}

Keywords: Qualitative Research; Biography; Critical Biography

\section{INTRODUCTION}

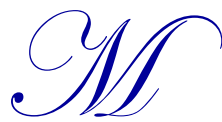

any academics would say that the value of quantitative research is considerably greater than the value of qualitative research because of its rigor, quantitative methodologies, data sets, and ability to test complicated hypotheses. Others defend qualitative research as being better able to represent the real world where shades of grey predominate and where research consumers (the readers) may not find qualitative methodology appealing or applicable. One author posits that "The quantitative and qualitative research traditions can be thought of as distinct cultures marked by different values, beliefs, and norms (Mahoney, 2006, p. 227). Others see merit in both and suggest that qualitative and quantitative methods actually rely on each other. Says Trochim (2006), all qualitative data can be quantified when ordered into themes and all quantitative data relies on the qualitative reporting of survey data where respondents are often asked to "grade" their answer on an arguably subjective Likert scale.

This paper focuses on one qualitative methodology, critical biography, as an appropriate method to examine management history luminaries and provide a context for their notable accomplishments. It further suggests that such critical biographies can provide a rich and interesting narrative that academics and practitioners alike can access and use to increase their understanding of management history. Before beginning, the author makes the case of the importance of knowledge of management history.

\section{THE IMPORTANCE OF MANAGEMENT HISTORY}

As a longtime member of the Academy of Management's Management History Division, the author has a keen interest in management history as a lens through which to analyze theory and practice in organizations today. Readers are asked to remember that the field of management is relatively new although it could be argued that managers have been around since any type of communal or team work existed. It is generally thought that Yale President, Henry Towne called for a new field of study in 1886 to deal with the growth of organizations and the productivity issues that accompanied this growth (Wren, 2005).

As to the importance of management history, books such as Wren \& Bedeian (2009) and George (1968) as well as articles such as Lamond (2005) and Gibson, Hodgetts, \& Blackwell (1999) have documented its value. Smith (2007) gave a particularly succinct description of the usefulness of management history: 
First, it increases our knowledge, wisdom and judgment of our profession. Second it increases our ability to understand and interpret the environmental conditions we are subject to and provides an awareness of the potentialities that exist. Third, it establishes collective memory and provides a communal identify. Fourth, it contributes to the moral good and good citizenship behavior of our students. Finally, it better enables us to pursue informed research that is rooted in and guided by past knowledge and accomplishments. (p. 531)

The illumination of management history seems a likely place for qualitative research methods in general and critical biography in particular.

\section{WHAT IS CRITICAL BIOGRAPHY?}

Biography is a well-known process of writing someone's life, often as a series of events portrayed in chronological fashion. Information is collected from multiple sources and presented in a way that gives meaning to the events that are described (Cresswell, 2007). Smith (1994) notes that biography can occur in many different forms including portrayals, memoirs, life stories, life histories, case studies, journals, diaries, autobiographies, and others.

Critical biography goes a step further by looking at critical incidents in the subject's life in order to "explore and explain the subject's scholarly development and intellectual contribution, situated in the social and historical background of the subject (Gibson, Chen, Henry, Humphreys, \& Lian, 2013, p. 442). In writing critical biography, the researcher inserts him or herself into the collected data to make interpretations and connections with contextual variables. Sometimes called "interpretive biography," critical biography has the elements of "focusing on a single individual, constructing a study out of stories and epiphanies of special events, situating them within a broader context, and evoking the presence of the author in the study" (Creswell, 2007, p. 88).

A useful format for writing critical biography can be found in Jacobs (2007) description of the four emphases he gave his students when researching important management figures: "the subject's values and background, important roles he or she held, contributions to theory and practice, and the social and historic context" (p. 105). Jacobs' discussion of how McGregor's roles as academic, human resource manager, and college president influenced his development of Theory $\mathrm{X}$ and $\mathrm{Y}$ makes a compelling story which is likely much more memorable than merely learning that Douglas McGregor is responsible for Theory X and Y. This heightened interest level is a key driver of the author's portrayal of critical biography as a meaningful methodology for discovering the secrets of management history.

Next, we look at several recent examples of how critical biography has been used to develop articles on key management figures.

\section{CRITICAL BIOGRAPHY MEETS MANAGEMENT HISTORY}

One way to illustrate how critical biography has been used in illuminating the work of management history notables is to use three recent articles as examples.

The first example is Abraham, Gibson, Novicevic, and Robinson's article, "Becoming an Outstanding Management Historian in the USA: Biographical Research of Wren's and Bedeian's Pathways," published in 2009 in the Journal of Management History. The authors use biography to "historicize outstanding academic leadership in the field of management history" (p. 9) by examining the intellectual and institutional pathways of the lives of Dan Wren and Art Bedeian that led to their widespread acceptance as the premiere management historians of our day. Say the authors, "The method of analyzing biographies of outstanding management historians, such as Wren and Bedeian, involves a procedural approach that combines history and interpretation to paint portraits of management of historians as observers and participants in their life stories" (p. 11). The authors used autobiographical material plus video and personal interviews to gather key biographical data and juxtapose it with the key contributions of each of these scholars. The authors concluded that:

Wren and Bedeian are ideological leaders who have been consistently defending the traditional values of management history as the repository of archived management knowledge. Their biographical data indicate that 
they nurture traditional values grounded in the rational paradigm of the Enlightenment. In other words, Wren's and Bedeian's education and professional experience have evolved on the assumption of a natural progress of management thought over time. (p. 17)

The next example is "Rhona Rapoport: A Critical Biography of a Pioneering Work-Family Researcher," by Russell Clayton and Harry Barton, published in The Journal of Applied Management and Entrepreneurship in 2011. The purpose of the authors was to "provide a critical biography of Rhona Rapoport as one of the founders of the work-family research area as we examine the social and gender-related aspects of the origins of work-family research" (2011, p. 24). This article provides an example of how critical biography can be used to illuminate the early days of a stream of research or a field of study, in this case, work-family research. The authors use Jacobs' (2007) four areas of inquiry to present the story of Rhona Rapoport and her work. These include Rapoport's values and background, her roles, her contributions to the field, and the historical and social times surrounding her work. To collect data, they relied on two previous interviews and an in-depth interview that they conducted themselves. They began their article by discussing current trends and research in the work-family area and then provided a discussion of how critical biography works. With this backdrop, a biographical sketch of Rapaport is provided along with her research accomplishments. Given the luxury of a living subject, the authors were able to ascertain Rapoport's views on field today as well as establish future directions for research.

Third, and most recently, Gibson, Chen, Henry, Humphreys, and Lian published "Examining the Work of Mary Parker Follett through the Lens of Critical Biography" in The Journal of Management History's October, 2013 issue. Unlike the previous article where personal interviews were possible, this article deals with a now deceased theorist and practitioner who had a tremendous influence on the evolution of the management field of study. Building on the inquiry areas suggested by Jacobs (2007), these authors examined the life of Mary Parker Follett, her mentors, other major influences including her gender and then reflected on this context while discussing her key ideas and contributions. The authors reflected that:

Mary Parker Follett was an anomaly of her times: a human relations futurist in the time of scientific management, an educated professional woman when neither attribute was typical, and an influential early management theorist....The context of her influence was an amalgam of life experiences and key factors such as her gender, her mentors, and her associates." (p. 456)

\section{DISCUSSION}

The previously discussed three articles serve as examples of the use of critical biography in exploring management history; they were chosen because they are approachable, informational, and interesting. They illustrate one qualitative method that requires rigor, attention to detail, and the ability to make connections between data about the person and contextual data which most likely influenced the person and his or her contributions. The result can be a much more memorable recounting of a significant person's contributions to the field because it brings life to the person and does not just relate their contributions in a matter-of-fact way.

How much more interesting to know, for example, that Lillian Gilbreth's foray into the human and psychological elements of management may not ever have happened had it not been that she was not allowed to study English literature with a well-known professor who did not allow women in his classes. As a consequence, Gilbreth began studying psychology and came under the influence of Edward Thorndike (Vasquez, 2007). How much more memorable to know that Mary Parker Follett engaged with top scholars in political science, psychology, history, and philosophy, but due to the norms of the time, had limited scholarly and occupational options. Instead she devoted "her time and intelligence to multiple community non-profit organizations," (Gibson et al., 2013, p. 447) and those experiences coincided with many of her key contributions in the areas of authority, power, and leadership. Thus, "the use of critical biography helps bring the past alive by bringing the background (historical, societal, and political contexts) in the open as a key determinant of professional contributions" (Gibson et al., 2013, p. 455).

Most of us would agree that what is more interesting to us is more memorable, what is placed in context makes more sense, and what is easy-to-read and understand is more likely to be accessed by a broader audience. 
Bringing the person to life makes that person more "real" and, hopefully, their contributions more understandable and appreciated. Further, the reader does not have to have quantitative skills to interpret critical biography, nor, for that matter, does the researcher need to have quantitative skills in order to tell the story.

However, the method is not without its limitations. It is important to acknowledge the bias of the researcher when drawing connections between biographical events and achievements. It is easy to follow a hunch about why someone did what they did and then look for biographical "proof" to back up one's theory. Instead it is important to take a comprehensive look at a person's life and let the story drive the discussion of why their contributions occurred when and as they did. As with all narrative research, it is important also to acknowledge the insertion of the researcher's own values and biases into his or her interpretation of the facts. While the researcher relies on his or her ability to uncover facts, observe, listen, and absorb, he brings into that mix his own skill set in synthesizing and extrapolating from that material to an interpretation of history. With all interpretation comes the very real issue of bias.

Successful critical biography relies on one's ability to tell a compelling story. In framing the story, it is important to stay as close to primary materials as possible and, when not possible, to use multiple sources in relating biographical data. Likewise the biographer needs to acknowledge his or her placement in the story; i.e., identifying opinion as different from fact. Given these limitations, critical biography seems a promising methodology for investigating the origin of ideas and the significant contributions of key people in almost any field. Every field has a history and that history and can and should shed light on the evolution of thought in that field.

As for future research opportunities, the possibilities are almost endless. Every field has pioneers and key contributors along the way. While much has been written about notables such as Barnard, Taylor, and Fayol, many others wait to step into the spotlight. In every case, critical biography can provide an alternative and interesting lens for the researcher.

\section{CONCLUSION}

In the words of Martin Luther King, "We are not makers of history. We are made by history." To be proficient in our professional fields, we need to be aware of the evolution of that field and the contributions of key contributors along the way. Those contributions in turn can be better understood in the historical, political, and social context of their life events. This paper suggests that critical biography is an effective methodology in achieving that goal.

\section{AUTHOR INFORMATION}

Jane Whitney Gibson is a Professor of Management at Nova Southeastern University where she teaches undergraduate and graduate courses in leadership, management and HR. Gibson is the author of four textbooks and numerous articles. Her current research interests focus on online education, leadership, and intergenerational values. Gibson serves as Editor of The Journal of Applied Management and Entrepreneurship and is a member of editorial boards for the Journal of Management History, Journal of Leadership and Organizational Studies, International Journal of Public Administration, and International Journal of Leadership. Jane Whitney Gibson, D.B.A., Professor, H. Wayne Huizenga School of Business and Entrepreneurship, Nova Southeastern University, Management Department, 3301 College Avenue, Ft. Lauderdale, FL 33314. E-mail: gibson@ nova.edu

\section{REFERENCES}

1. Abraham, D. R., Gibson, M. C., Novicevic, M. M., \& Robinson, R. K. (2009). Becoming an outstanding management historian in the USA: Biographical research of Wren's and Bedeian's pathways. Journal of Management History, 15(1), 9-19.

2. Clayton, R. W., \& Barton, H. (2011). Rhona Rapoport: A critical biography of a pioneering work-family researcher. The Journal of Applied Management and Entrepreneurship, 16(3), 23-33.

3. Creswell, J. W. (2007). Qualitative inquiry and research design. Thousand Oaks, CA: Sage Publications. 
4. Gibson, J. W., Chen, W., Henry, E., Humphreys, J., \& Lian, Y. (2013). Examining the work of Mary Parker Follett through the lens of critical biography. Journal of Management History, 19(4), 441-458.

5. Gibson, J. W., Hodgetts, R. M., \& Blackwell, C. W. (1999). The role of management history in the management curriculum: 1997. Journal of Management History, 5(5), 277-285.

6. Graham, L. D. (1994). Critical biography without subjects and objects: An encounter with Dr. Lillian Moller Gilbreth. The Sociological Quarterly, 35(4), 621-643.

7. Jacobs, D. (2007). Critical biography and management education. Academy of Management Learning \& Education, 6(1), 104-108.

8. Lamond, D. A. (2005). On the value of management history: Absorbing the past to understand the present and inform the future. Management Decision, 42(10), 1273-1281.

9. Mahoney, J., \& Goertz, G. (2006). A tale of two cultures: Contrasting quantitative and qualitative research. Political Analysis, 14(3), 227-249.

10. Russell, P. (2009). The "art” of critical biography. Journal of Women's History, 21(4), 152-156.

11. Smith, G. E. (2007). Management history and historical context: Potential benefits of its inclusion in the management curriculum. Academy of Management Learning \& Education, 6(4), 522-533.

12. Smith, L. M. (1994). Biographical method. In N. K. Denzin \& Y. S. Lincoln (eds), Handbook of qualitative research (pp. 286-305). Thousand Oaks, CA: Sage.

13. Trochim, S. (2006). The qualitative debate. In the Research Methods Knowledge Base of the Web Center for Social Research Methods. Retrieved from http://www.socialresearchmethods.net/kb/qualdeb.php

14. Vasquez, M. J. T. (2007). Lillian Evelyn Moller Gilbreth: The woman who "had it all." In E. A. Gavin, A. J. Clamar, \& M. A. Siderits (Eds.), Women of vision: Their psychology, circumstances, and success (pp. 45-60). New York: Springer.

15. Wren, D. A. (2005). The history of management thought ( $5^{\text {th }}$ ed.). New York: John Wiley \& Sons, Inc.

16. Wren, D. A., \& Bedeian, A. G. (2009). The evolution of management thought (6 ${ }^{\text {th }}$ ed.). NY: John Wiley \& Sons, Inc. 
\begin{tabular}{ll} 
International Journal of Management \& Information Systems - Third Quarter $2014 \quad$ Volume 18, Number 3 \\
\hline
\end{tabular}

NOTES 